\title{
GAYA MANAJEMEN KONFLIK DAN KEPRIBADIAN
}

\author{
Rahma Safitri, Omar K. Burhan, Zulkarnain \\ Universitas Sumatera Utara
}

\begin{abstract}
ABSTRAK
Penelitian ini bertujuan untuk memeriksa peran dimensi kepribadian Big-Five dalam menentukan gaya manajemen konflik seseorang. Individu yang memiliki kepribadian openness yang tinggi menunjukkan kecenderungan untuk melakukan berbagai gaya manajemen konflik sekaligus (compromising, integrating, obliging, dan dominating). Individu yang memiliki derajat kepribadian conscientiousness yang tinggi berasosiasi dengan gaya manajemen konflik compromising. Individu dengan kepribadian extraversion yang tinggi cenderung menggunakan mengelola konflik dengan gaya integrating dan menghindari gaya avoiding. Derajat kepribadian agreeableness yang tinggi berasosiasi positif dengan gaya manajemen konflik compromising dan integrating. Terakhir, kepribadian neuroticism yang tinggi berasosiasi positif dengan gaya manajemen konflik avoiding. Diskusi kami fokuskan dengan membahas implementasi pengukuran kepribadian untuk memprediksikan gaya manajemen konflik dalam proses assessment dan perekrutan tenaga kerja.
\end{abstract}

Kata-kata kunci: Kepribadian, gaya manajemen konflik, assesment tenaga kerja

\section{CONFLICT MANAGEMENT STYLES AND PERSONALITY}

\section{ABSTRACT}

In the present research, we examined the roles of the Big-Five personality dimensions in predicting individual's conflict management approach. Individuals with high degree of openness tended to show multiple conflict management approach (compromising, integrating, obliging, and dominating). Individuals with high degree of conscientiousness is associated with the compromising conflict management style. Individuals with high degree of extraversion are more likely to approach conflict through the integrating style and less likely to enggage with the avoiding style. High agreeableness is associated with both the compromising and integrating approach. Finally, neuroticism is associated with the avoiding style. We focussed the Discussions section on the implementation of personality assessment in employee's job assessment and recruitment process as means of predicting individuals' tendency of conflict management.

Keywords: Personality; conflict management style, and employee assesment.

Konflik dapat terjadi ketika terjadi ketidaksesuaian tindakan dan tujuan individu-individu yang terlibat. Di satu sisi, konflik dapat menimbulkan kerugian apabila resolusi tidak tercapai. Di sisi lain, dapat memberikan berbagai keuntungan apabila resolusi tercapai (Winardi, 2007). Inilah yang mungkin menjadi alasan pentingnya pengelolaan konflik yang efektif dalam kehidupan keorganisasian. McShane dan Glinov (2003) mencontohkan, kegagalan dalam resolusi konflik antar individu di dalam suatu departemen atau organisasi dapat menimbulkan perasaan cemas yang berkepanjangan dan persaingan antar individu yang terlibat. Sebagai dampaknya, individu-individu yang terlibat dapat melupakan tujuan pokok

*Korespondensi mengenai penelitian ini dapat dilayangkan kepada Rahma Safitri melalui e-mail: safitri_rahma@yahoo.com organisasi. Hal ini sangat berbeda apabila pihak-pihak yang terlibat mencapai kesepakatan menggunakan cara-cara yang baru dalam meraih tujuan mereka, sehingga kreativitas dari masing-masing pihak bertambah baik. Hal ini senada dengan Mullins (2004) yang menyatakan bahwa banyaknya perbedaan perilaku antara individu dapat mengakibatkan konflik dan setiap individu di dalam organisasi membutuhkan manajemen konflik yang baik agar konflik tidak merugikan diri individu dan organisasi yang terlibat.

\section{GAYA MANAJEMEN KONFLIK}

Manajemen konflik merupakan pengelolaan konflik yang tidak hanya

Rekomendasi mensitasi:

Safitri, R., Burhan, O. K., \& Zulkarnain. (2013). Gaya manajemen konflik dan kepribadian. Psikologia, 8(2), 39-49. 
berfokus pada menghindari, mengurangi, atau menghilangkan konflik, namun juga melibatkan perancangan strategi yang dapat membuat konflik justru menjadi dasar perolehan insight dalam pengembangan organisasi dan individuindividu yang menjadi bagian dari organisasi tersebut (Rahim, 2010; Ujan dkk., 2011; Winardi, 2007). Menurut Rahim (2010), individu dapat melakukan berbagai strategi atau gaya dalam memanajemen konflik, yaitu: (1) Integrating, (2) obliging, (3) dominating, (4) compromising (5) dan avoiding. Berikut adalah penjelasannya.

Pada gaya integrating, individu berfokus pada keuntungan maksimum dan seimbang bagi pihak-pihak yang terlibat pertikaian. Orang dengan gaya ini berfokus agar pihak-pihak yang terlibat dapat berpartisipasi aktif dalam pemecahan masalah, sehingga kedua pihak dapat mendapatkan hasil yang saling menguntungkan. Pada gaya obliging, individu cenderung 'mengalah' dengan pihak lainnya, sehingga individu cenderung merelakan kepentingannya, sedangkan pihak lainnya dapat memperoleh keuntungan maksimum. Pada gaya dominating, individu sangat menekankan kekuatannya di atas pihak lainnya, dan sangat berfokus pada kepentingannya, serta tidak menghiraukan kepentingan pihak lainnya. Sebagai konsekuensi, individu dengan gaya ini cenderung 'ngotot' untuk memperoleh keuntungan maksimum bagi diri atau kelompok yang ia wakilkan dan merugikan pihak lainnya. Pada gaya avoiding, individu memiliki perilaku acuh, yang tidak menghiraukan kepentingannya sendiri, maupun pihak lainnya. Individu dengan gaya manajemen konflik seperti ini cenderung menghindar ketika konflik muncul. Pada gaya compromising, individu berupaya menyelesaikan konflik dengan cara mencari 'jalan tengah' yang memuaskan sebagian kepentingan dirinya dan sebagian kepentingan pihak lainnya. Perbedaan mendasar antara compromising dan integrating terletak pada fokus keuntungan yang ingin dicapai. Sementara gaya integrating berfokus pada keuntungan maksimum bagi kedua belah pihak, compromising hanya berfokus pada hasil yang bersifat 'setengah-setengah'. Jadi, di dalam compromising, keuntungan maksimum tidak dapat dicapai, setiap pihak yang terlibat harus merelakan sebagian kepentingannya dan mempertahankan sebagian kepentingannya yang lain.

\section{KEPRIBADIAN}

Kepribadian

merupakan karakteristik seseorang yang terlihat dari pola perasaan, berpikir, dan berperilaku yang konsisten (Pervin, 2005). Sedangkan Feist dan Feist (2009) mendefinisikan kepribadian sebagai sifat, kecenderungan, dan karakteristik individu yang permanen, yang mempengaruhi perilaku individu secara konsisten. Mengacu pada McCrae dan Costa (1992), kepribadian individu terdiri atas lima dimensi utama, yang disebut sebagai Big-Five. Lima dimensi tersebut adalah (1) openness, conscientiousness, (3) extraversion, (4) agreeableness, dan (5) neuroticism. Berikut adalah penjelasannya.

Dimensi openness mengacu pada kecenderungan individu untuk mencari kesenangan terhadap pengalaman baru, artistik, keinginan untuk menjadi mandiri, dan imajinatif. Conscientiousness mencacu pada kecenderungan untuk menjadi orang yang terorganisir, tekun, bermotivasi, dapat diandalkan, efisien, dan penuh perencanaan. Extraversion mengacu kepada kecenderungan untuk dapat bersosialisasi, cerewet, aktif, tegas, optimis, dan antusias. Agreeableness mengacu kepada kecenderungan untuk berhati lembut, baik hati, dapat dipercaya, pemaaf, appresiatif, dan suka menolong. Terakhir, neuroticism mengacu kepada kecenderungan untuk memiliki ketidakstabilan emosi, ide-ide yang tidak realistis, pencemas, sensitif, mengasihani 
diri sendiri. Sebagaimana akan kami jelaskan lebih lanjut, dimensi-dimensi kepribadian ini merupakan hal yang dapat menentukan pemilihan individu terhadap gaya-gaya manajemen yang dipilihnya ketika berhadapan dalam situasi konflik dengan orang lain.

\section{KEPRIBADIAN DAN GAYA MANAJEMEN KONFLIK}

Sebagaimana telah kami sebutkan, kepribadian merupakan faktor yang penting yang menentukan perilaku individu, termasuk juga dalam hal pemilihan gaya manajemen konflik (Ahmed, 2010; Deutsch, 2000; Burn, 2004).

Banyak peneliti yang melakukan penelitian yang berhubungan dengan kepribadian dan gaya manajemen konflik, dari penelitian yang ada didapatkan persamaan dan perbedaan. Berikut adalah penjelasannya.

\section{Big-Five dan gaya manajemen konflik Compromising}

$\begin{array}{ccr}\text { Gaya } & \text { manajemen } & \text { konflik } \\ \text { compromising, } & \text { merupakan } & \text { gaya }\end{array}$ manajemen konflik dengan cara bertukar pendapat dengan pihak lawan tetapi tidak terlalu berfokus pada kemenangan (Rahim, 2001). Adanya pertukaran pendapat dengan pihak lain mengarahkan gaya manajemen konflik ini kepada ciri kepribadian openness (Hipotesa 1a) yang senang dengan hal- hal baru termasuk pendapat atau ide dari orang lain (Costa \& McRae, 1987; Goel \& Khan, 2012) tetapi tidak dengan individu yang memiliki emosi yang tidak stabil dan pencemas (neuroticism: Hipotesa 1e; Goel \& Khan, 2012). Melakukan pertukaran pendapat akan lebih mudah dilakukan jika orang yang terkait dapat bersosialisasi dan mudah percaya dengan orang lain, sehingga individu dengan kepribadian extraversion (Hipotesa 1c) dan agreeableness (Hipotesa 1d) kemungkinan besar akan menggunakan gaya manajemen konflik compromising (Osuch \& Lewandawski, 2004)

Gaya manajemen konflik compromising yang tidak berfokus kepada kemenangan tidak sesuai dengan individu yang memiliki kepribadian conscientiousness, karena conscientiousness merupakan kepribadian yang memiliki keinginan tinggi, terorganisir dan berfokus kepada kemenangan (Costa \& Mcrae, 1992). Dengan demikian, secara logis, kepribadian conscientiousness seharusnya berkorelasi negatif dengan gaya manajemen konflik compromising (Hipotesis 1b). Namun, perlu dicatat, berdasarkan penelitian Osuch dan Lewandawski (2004) penalaran logis ini tidak didukung oleh penelitian sebelumnya yang mengindikasikan ketiadaan hubungan antara conscientiousness dengan gaya manajemen konflik compromising.

\section{Big-Five dan gaya manajemen konflik Integrating}

Integrating merupakan gaya manajemen konflik yang berfokus kepada bagaimana kedua belah pihak yang berkonflik berpartisipasi aktif dalam kegiatan pemecahan masalah sehingga mendapatkan hasil yang saling menguntungkan. Lee (2008) mengatakan bahwa gaya manajemen konflik ini bersifat terbuka, mau bertukar informasi dengan pihak lain dan menyatukan perbedaan untuk mencari solusi yang terbaik bagi kedua pihak. Gaya manajemen konflik ini juga dianggap kompeten karena menyelesaikan dengan mencari tahu tujuan, persepsi atau ide dari pihak lain kemudian mencari solusi secara bersamasama (Tutzauer and Roloff, 1988; Lee, 2008). Sejalan dengan ini, individu yang memiliki derajat kepribadian openness yang tinggi dicirikan dengan sifat terbuka dan mau melihat perspektif-perspektif baru (Feist \& Feist, 2009), sehingga mereka lebih mungkin untuk mengelola konflik dengan pendekatan integrating. Hal ini sesuai dengan penelitian yang dilakukan 
oleh Iqbal, Ejaz dan Ara (2012) tentang kepribadian dan gaya manajemen konflik pada operator call-centre, yang menunjukkan bahwa kepribadian openness akan lebih mudah untuk berintegrasi dengan orang lain (Hipotesa 2a). Selain, openness, menurut penelitian yang dilakukan Osuch dan Lewandowski (2004) kepribadian extraversion, agreeableness dan conscientiousness juga dapat berasosiasi dengan gaya manajemen konflik integrating. Menurut mereka, kepribadian extraversion memiliki ciri assertif yang merupakan satu hal yang penting untuk gaya manajemen konflik integrating. Dengan demikian, dimensi kepribadian extraversion selayaknya berasosiasi positif dengan gaya manajemen konflik integrating (Hipotesa 2c). Selanjutnya, individu-individu yang memiliki tingkat agreeableness yang tinggi, memiliki kecenderungan perilaku prososial yang tinggi, yang membuat mereka lebih mungkin untuk melakukan aksi-aksi yang dapat menguntungkan diri dan orang lain yang terlibat konflik (Hipotesa 2d). Pendekatan integrating mensyaratkan motivasi yang tinggi untuk mencapai solusi yang terbaik bagi kedua pihak, hal ini yang membuat individu yang tinggi pada dimensi conscientiousness juga sangat mungkin untuk mengelola konflik melalui gaya manajemen ini (Hipotesa $2 b$ ). Terakhir, individu yang tinggi pada dimensi neuroticsm memiliki cenderung sulit mengelola stres dan tekanan, padahal pengelolaan konflik yang bersifat integrating tentunya mensyaratkan kemampuan regulasi emosi dan stres yang baik. Sebagai implikasi, individu yang memiliki derajat neuroticism yang tinggi akan lebih mungkin menghindari pendekatan pengelolaan konflik yang bersifat integrating (Hipotesa 2e).

\section{Big-Five dan gaya manajemen konflik Obliging}

Gaya manajemen konflik yang ketiga adalah obliging yang merupakan gaya manajemen konflik dengan cara mengorbankan kepentingan pribadi dan mengutamakan kepentingan orang lain (Rahim, 2001). Kecenderungan mengutamakan kepentingan orang lain mengarah kepada kecenderungan untuk merasa senang menolong orang lain. Rasa senang menolong orang lain merupakan salah satu ciri dari kepribadian agreeableness (Costa \& Mcrae, 1992). Jadi, besar kemungkinan bagi individu yang memiliki derajat kepribadian agreeableness yang tinggi untuk melakukan obliging sebagai pendekatannya dalam mengelola koflik (Hipotesis 3d: Goel \& Khan, 2012). Mengacu pada Goel dan Khan (2012), kecemasan yang dimiliki individu yang tinggi pada dimensi kepribadian neuroticism membuat mereka cenderung patuh dan tunduk kepada orang lain, sehingga besar kemungkinan bagi mereka untuk menggunakan gaya obliging dalam mengelola konflik (Hipotesa 3e). Berbeda dengan dua dimensi kepribadian sebelumnya, penelitian yang dilakukan oleh Goel dan Khan (2012) menunjukkan bahwa kepribadian openness, conscientiousness dan extraversion cenderung tidak menggunakan gaya manajemen konflik obliging. Hal ini karena kepribadian openness bercirikan keinginan yang tinggi untuk hal-hal baru dan bersifat independen (Hipotesa 3a), kepribadian conscientiousness bercirikan motivasi yang tinggi dan penuh perencanaan (Hipotesa 3b), serta kepribadian extraversion memiliki rasa optimis akan tujuannya (Costa \& Mcrae, 1992) (Hipotesa 3c). Sehingga membuat ketiga kepribadian ini cenderung tidak menyerah kepada pihak lawan.

\section{Big-Five dan gaya manajemen konflik Dominating}

Gaya manajemen konflik yang keempat adalah dominating, yang memanajemen konflik dengan cara mendominasi atau menguasai pihak lawan dengan segala cara untuk menang (Rahim, 2001). Hasil penelitian yang dilakukan 
Akrami dan Ekehammar (2006) mengenai sosial-dominance dengan kepribadian openness dan agreeableness, menunjukkan tidak adanya hubungan antara ketiganya. Hasil penelitian ini sejalan dengan penelitian Osuch dan Lewandowski (2004) yang mengatakan tidak ada korelasi antara gaya manajemen konflik dominating dengan kepribadian openness, agreeableness, conscientiousness dan neuroticism tetapi berhubungan dengan dimensi kepribadian extraversion (Hipotesa 4c). Hal ini dikarenakan individu yang extrovert memiliki kecenderungan alami untuk bersikap agresif dan mendominasi (Eysenck, 1985; Zawadzki and team, 1998; Osuch \& Lewandowski, 2004). Sedangkan kepribadian openness merupakan kepribadian yang senang mendengarkan opini orang lain (Hipotesa 4a), agreeableness merupakan kepribadian yang simpatik dan lemah lembut (Hipotesa 4d), conscientiousness merupakan kepribadian yang bertanggung jawab, dan neuroticsm merupakan kepribadian yang tempramen dan pencemas yang tinggi (Costa \& Mcrae, 1992) (Hipotesa 4e).

\section{Big-Five dan gaya manajemen konflik Avoiding}

Gaya manajemen konflik yang kelima adalah avoiding, yang merupakan gaya manajemen konflik dengan cara menghindari konflik (Rahim, 2001). Sikap menghindari merupakan salah satu ciri dari kepribadian yang introvert, karena kecemasan dan merasa tidak ada kemampuan untuk bersosialisasi dengan orang lain karena rasa malu dan tertutup mereka (Osuch \& Lewandowski , 2004). Rasa cemas adalah bagian dari kepribadian neuroticsm (Costa \& Mcrae, 1992). Sehingga, individu dengan neuroticsm yang tinggi cenderung akan menghindar jika berhadapan dengan konflik (Goel \& Khan, 2012) (Hipotesa 5e). Orang dengan kepribadian agreeableness yang tinggi juga akan cenderung menghindari konfrontasi dengan konflik untuk melindungi ketertarikan pribadinya (Antonioni, 1998) (Hipotesa 5d). Berbeda dengan keduanya, dimensi kepribadian lain yang memiliki orientasi seperti openness merupakan kepribadian yang senang akan hal baru termasuk mendengarkan opini orang lain, conscientiousness merupakan kepribadian yang bertanggung jawab dan berkeinginan kuat, extraversion yang senang bersosialisasi, aktif dan optimis akan tujuannya (Costa \& Mcrae, 1992) akan cenderung menghadapi konflik yang ada. Hal ini sejalan dengan penelitian yang dilakukan Goel \& Khan (2012) yang menunjukkan tidak ada hubungan antara openness, conscientiousness dan extraversion dengan gaya manajemen konflik avoiding, hal ini dikarenakan ciriciri dari ketiga dimensi kepribadian tidak mengarah kepada penghindaran akan sesuatu (Hipotesa 5a, 5b, dan 5c).

\section{METODE}

\section{Partisipan}

Partisipan dalam penelitian ini merupakan mahasiswa Universitas Sumatera Utara, berjumlah 204 orang (147 perempuan, dan 57 laki-laki, $M_{\text {usia }}=20.67$, $S D=1.28$ ). Jumlah partisipan menurut fakultas adalah fakultas psikologi 50 orang, fakultas kedokteran 11 orang, fisip 11 orang, FIB 9 orang, fakultas teknik 12 orang, fakultas Teknik Informatika 7 orang, Fakultas farmasi 10 orang, fakultas MIPA 12 orang, fakultas Ekonomi 15 orang, fakultas hukum 14 orang, fakultas keperawatan 19 orang, fakultas kedokteran gigi 11 orang, fakultas pertanian 9 orang, dan fakultas kesehatan masyarakat 14 orang.

\section{Alat ukur \\ Skala kepribadian Big Five}

Alat ukur kepribadian yang digunakan dalam penelitian ini adalah skala Big-five yang telah diadaptasi ke dalam bahasa indonesia agar dapat lebih mudah dipahami dan sesuai dengan 
kondisi individu di Indonesia. Alat ukur ini terdiri dari item favourable dan unfavourable. Di mana subjek diminta untuk memilih "STS" (sangat tidak setuju), "TS" (tidak setuju), "N" (netral), "S" (setuju), atau "SS" (sangat setuju). Setiap aitem favourable akan diberikan skor $1=$ "STS", 2 = "TS", hingga $5=$ "SS". Sedangkan untuk aitem unfavourable akan diskor sebaliknya.

Pengujian validitas alat ukur pada skala ini menggunakan construct validity yaitu analisis faktor, dimana pengujian menggunakan tes KMO (Kaiser-MeyerOlkin Measure of Sampling Adequacy). Menurut Kaiser (1974; Field, 2009) nilai terkecil KMO sebaiknya harus 0.5. Nilai KMO yang kecil menunjukkan bahwa data tidak cocok dianalisis dengan menggunakan analisis faktor. Selanjutnya pengujian melihat nilai Measure of Sampling Adequacy (MSA), menurut Field (2009) nilai MSA akan lebih baik jika diatas 0.5. Pengujian analisis faktor juga melihat nilai eigenvalue, dimana nilai eigenvalues dari masing-masing faktor harus lebih dari 1. Pengujian analasisi faktor yang terakhir dengan melihat nilai bobot faktor (factor loading), nilai factor loading yang biasa digunakan oleh peneliti adalah diatas 0.3 (Field, 2009).

Dimensi extraversion diperoleh 5 aitem, dengan nilai KMO sebesar .746, nilai MSA yang bergerak dari .688 sampai .827 , nilai eigenvalue sebesar $47.248 \%$, dan nilai factor loading bergerak dari .546 sampai .842. Pada dimensi agreeableness diperoleh 4 aitem, dengan nilai KMO sebesar .660, nilai MSA yang bergerak dari .617 sampai .724, nilai eigenvalue sebesar $51.051 \%$, dan nilai factor loading yang bergerak dari .371 sampai .835. Pada dimensi conscientiousness diperoleh 4 aitem, dengan nilai KMO sebesar .708, nilai MSA yang bergerak dari .670 sampai .820 , nilai eigenvalue sebesar $52.665 \%$ dan nilai factor loading bergerak dari .564 sampai .818. Pada dimensi neuroticsm diperoleh 6 aitem, dengan nilai KMO sebesar .831, nilai MSA yang bergerak dari .717 sampai dengan .893, nilai eigenvalue sebesar $34.809 \%$, dan nilai factor loading yang bergerak dari .465 sampai dengan .868. Pada dimensi yang terakhir yaitu dimensi openness diperoleh 7 aitem, dengan nilai KMO sebesar .830, nilai MSA yang bergerak dari .741 sampai .890, nilai eigenvalue sebesar $18.557 \%$, dan nilai factor loading bergerak dari .305 sampai .761.

Skala ini terdiri dari 26 aitem dengan nilai koefisien alpha openness $(\alpha=$ .854), neuroticsm $(\alpha=.820)$, conscientiousness $(\alpha=$.699), agreeableness $(\alpha=.718)$, dan extraversion $(\alpha=.718)$.

\section{Skala gaya manajemen konflik}

Gaya manajemen konflik pada penelitian ini akan diukur dengan menggunakan skala yang dikembangkan oleh Rahim pada tahun 1993. Gaya manajemen konflik ini ada lima yaitu integrating, obliging, dominating, compromising, dan avoiding. Skala ini memiliki nilai $\alpha=.845$, dengan pengujian validitas yang menggunakan analisis faktor. Hasil uji analisis faktor gaya integrating diperoleh 4 aitem dengan nilai KMO sebesar .634, nilai MSA bergerak dari .601 sampai dengan .700, nilai eigenvalue sebesar $41.91 \%$, dan nilai factor loading bergerak dari .613 sampai .763. Pada gaya compromising diperoleh 2 aitem dengan nilai KMO sebesar .500, nilai MSA sebesar .500, nilai eigenvalue sebesar $58.18 \%$, dan nilai factor loading sebesar .763. Pada gaya dominating diperoleh 5 aitem dengan nilai KMO sebesar .790, nilai MSA bergerak dari .758 sampai .823, nilai eigenvalue sebesar $54.672 \%$, dan nilai factor loading bergerak dari .612 sampai .814. Pada gaya obliging diperoleh 4 aitem dengan nilai KMO sebesar .729, nilai MSA yang bergerak dari .659 sampai dengan .778, nilai eigenvalue sebesar $35.794 \%$ dan nilai factor loading yang bergerak dari .622 sampai .877. Pada gaya manajemen konflik yang terakhir yaitu avoiding diperoleh 4 aitem, dengan nilai KMO 
sebesar .634, nilai MSA bergerak dari .595 sampai .687, nilai eigenvalue sebesar $47.344 \%$ dan nilai factor loading yang bergerak dari .621 sampai .784 .

\section{HASIL}

Untuk menguji hipotesis-hipotesis penelitian, kami mengaplikasikan teknik analisis korelasi pearson. Hasil secara umum dapat dilihat pada Tabel 1. Sebagaimana tergambarkan pada Tabel 1, hanya sebagian hipotesa yang diajukan yang mendapatkan dukungan empiris. Sesuai dengan Hipotesis 1a, 1d semakin tinggi derajat kepribadian openness $(r=$ $.169, p=.020)$, dan agreeableness $(r=$ $.164, p=.019)$ semakin tinggi kecenderungan individu untuk melakukan gaya manajemen konflik compromising. Hasil analisis regresi menunjukkan bahwa kepribadian yang paling kuat memprediksi gaya manajemen konflik compromising adalah dimensi kepribadian agreeableness $\left(R^{2}=.029\right)$, di mana dimensi kepribadian ini berkontribusi sebanyak $2.9 \%$ dalam gaya manajemen konflik compromising. menggunakan gaya manajemen konflik obliging juga semakin tinggi. Dimensi kepribadian openness berkontribusi sebesar $\left(R^{2}=.031\right)$, yang berarti hanya berkontribusi sebesar $3.1 \%$ dalam gaya manajemen konflik obliging. Terakhir, hasil menunjukkan hipotesis $5 \mathrm{~d}$ dan $5 \mathrm{e}$ yaitu semakin tinggi derajat kepribadian extraversion ( $r=-.158, p=.024)$ dan neuroticsm ( $r=.178, p=.011)$ seseorang, semakin tinggi juga kecenderungannya menggunakan gaya manajemen konflik avoiding. Hasil analisis regresi menunjukkan bahwa dimensi kepribadian yang paling berkontribusi dalam avoiding adalah neuroticsm $\left(R^{2}=.032\right)$, yang bahwa dimensi kepribadian neuroticsm berkontribusi sebesar $3.2 \%$ dalam gaya manajemen konflik avoiding.

Selanjutnya, terdapat beberapa hipotesa yang tidak sesuai dengan hasil korelasi yaitu hipotesa $1 \mathrm{~b}$ dan 4a. Hasil menunjukkan adanya hubungan positif antara kepribadian conscientiousness dengan compromising $(r=.148, p=.035)$ dan kepribadian opennes dengan dominating ( $r=.166, p=.023)$. Dimensi

Tabel 1 Matriks korelasi kepribadian dan gaya manajemen konflik

\begin{tabular}{lccccc}
\hline & Openness & Conscientiousness & Extraversion & Agreeableness & Neuroticism \\
\hline Compromising & $.169^{*}$ & $.148^{*}$ & .006 & .164 & -.059 \\
Integrating & $.270^{\star *}$ & .078 & .178 & $.164^{*}$ & .052 \\
Obliging & $.177^{*}$ & -.058 & -.020 & .094 & .101 \\
Dominating & $.166^{*}$ & -.104 & -.031 & -.031 & .020 \\
Avoiding & .021 & -.113 & $-.158^{\star}$ & .002 & $.178^{*}$ \\
\hline
\end{tabular}

Hasil pengujian juga mendukung Hipotesis 2a, 2c, dan 2d yaitu semakin tinggi derajat kepribadian openness $(r=$ $.270, p=.001)$, extraversion $(r=.178, p=$ $.011)$ dan agreeableness $(r=.164, p=$ .019) seseorang, semakin tinggi juga kecenderungannya menggunakan gaya manajemen konflik integrating. Hasil analisis regresi menunjukkan bahwa kepribadian yang paling kuat memprediksi gaya manajemen konflik integrating adalah openness $\left(R^{2}=.073\right)$, yang berarti dimensi kepribadian openness hanya berkontribusi sebesar $7.3 \%$. Hipotesa $3 \mathrm{a}$ juga menunjukkan bahwa semakin tinggi derajat kepribadian openness $(r=.177, p$ $=.015)$ seseorang maka kecenderungan kepribadian openness berkontribusi sebesar $R^{2}=.028$, yang berarti memiliki kontribusi hanya sebesar $2.8 \%$ pada gaya manajemen konflik dominating. Selain itu, dukungan hipotesis juga tidak didapatkan untuk Hipotesis 1c, 1e, 2b, 2e, 3b, 3c, 3d, $3 \mathrm{e}, 4 \mathrm{~b}, 4 \mathrm{c}, 4 \mathrm{~d}, 4 \mathrm{e}, 5 \mathrm{a}, 5 \mathrm{~b}$, dan $5 \mathrm{c}$ yaitu kepribadian extraversion dan neuroticsm tidak memiliki hubungan dengan gaya manajemen konflik compromising, kepribadian conscientiousness dan neuroticsm tidak memiliki hubungan dengan gaya manajemen konflik integrating, kepribadian conscientiousness, extraversion, agreeableness, neuroticsm tidak memiliki hubungan dengan gaya manajemen konflik obliging. Kepribadian 
conscientiousness,

extraversion,

agreeableness dan neuroticsm tidak memiliki hubungan dengan gaya manajemen konflik dominating. Kepribadian openness, conscientiousness, dan extraversion tidak memiliki hubungan dengan gaya manajemen konflik avoiding.

\section{DISKUSI}

Secara spesifik, individu dengan derajat kepribadian openness, conscientiousness dan agreeableness yang tinggi berkorelasi positif dengan gaya manajemen konflik compromising. Ada beberapa alasan kepribadian ini berkorelasi dengan gaya manajemen konflik compromising. Pertama, Kepribadian openness merupakan kepribadian yang original, bebas, kreatif (Schultz \& Schultz, 1993), senang mencari pengalaman dan hal-hal baru untuk diri (Pervin, 2005) sehingga untuk memilih compromising, sebagai gaya manajemen konfliknya merupakan hal yang sesuai karena menurut Rahim (2001) dalam gaya manajemen konflik compromising dilakukan pertukaran informasi dan keterbukaan serta menyatukan perbedaan untuk mendapatkan solusi. Beberapa hal tersebut sesuai dengan kepribadian openness yang menyukai hal-hal baru seperti informasi dari pihak lain.

Kedua,

kepribadian conscientiousness merupakan kepribadian yang tekun, ambisius dan teratur, pekerja keras, gigih dan tepat waktu (Feist\&Feist, 2009), berhati-hati dan dapat diandalkan (schultz \& schultz, 1993). Individu dengan kepribadian ini berorientasi kepada tujuannya dan ambisius untuk meraih apa yang diinginkan tetapi dengan cara yang teratur. Dimensi kepribadian ini sesuai dengan gaya manajemen konflik compromising karena menurut Rahim (2002) ketika gaya manajemen konflik lain tidak dapat digunakan dikarenakan dua pihak memiliki kekuatan yang sama sehingga tidak mendapatkan solusi yang terbaik maka gaya manajemen konflik ini merupakan pilihan yang tepat.
Ketiga, kepribadian agreeableness merupakan kepribadian yang suka menolong dan mudah percaya dengan orang lain (Costa \& Mcrae, 1992), sedangkan gaya manajemen konflik compromising adalah gaya manajemen konflik yang dilakukan dengan cara bertukar pendapat (Rahim, 2001). Sehingga, jika ada kepercayaan antar dua pihak akan memudahkan untuk melakukan kesepakatan dengan bertukar pendapat. Osuch dan Lewandawski (2004) mengatakan pertukaran pendapat akan lebih mudah dilakukan jika pihak yang terkait dapat bersosialisasi dan dapat dipercaya.

Hasil analisis yang selanjutnya menunjukkan bahwa individu dengan derajat kepribadian openness extraversion dan agreeableness berkorelasi positif dengan gaya manajemen konflik integrating. Beberapa alasan adanya korelasi antara keduanya adalah pertama, dimensi kepribadian openness merupakan kepribadian yang original, bebas, kreatif (Schultz \& Schultz, 1993), senang mencari pengalaman dan hal-hal baru untuk diri (Pervin, 2005) sehingga akan sesuai jika memilih integrating, sebagai gaya manajemen konfliknya karena menurut Rahim (2001) dalam gaya manajemen konflik integrating juga dilakukan pertukaran informasi dan keterbukaan serta menyatukan perbedaan untuk mendapatkan solusi, beberapa hal tersebut sesuai dengan kepribadian openness yang menyukai halhal baru seperti informasi dari pihak lain. Hanya saja yang membedakan gaya manajemen konflik ini dengan gaya manajemen konflik compromising adalah integrating berfokus pada solusi "menangmenang" sedangkan compromising tidak ada fokusan lebih, yaitu tidak menang atau tidak kalah. Berbeda dengan gaya manajemen konflik dominating yang dijelaskan Rahim yaitu berfokus pada kemenangan atau "menang-kalah" (Rahim, 2001). Kedua, dimensi kepribadian extraversion merupakan kepribadian yang dapat bersosialisasi, 
mencintai kesenangan, aktif dan optimis (Feist \&Feist, 2009). Jika kepribadian ini dihadapkan kepada suatu permasalahan yang sangat kompleks, maka individu dengan kepribadian ini akan lebih optimis dapat menyelesaikan konfliknya dan karena individu dengan kepribadian ini dapat bersosialisasi dengan mudah maka penyelesaian konfliknya dapat dengan cara memberikan solusi yang menguntungkan kepada kedua pihak. Hal ini sejalan dengan pendapat Rahim (2002) bahwa untuk menggunakan gaya manajemen konflik integrating dibutuhkan komitmen yang kuat dari kedua pihak, dan pertukaran informasi dari kedua pihak dapat membuat solusi yang lebih baik. Ketiga, kepribadian agreeableness merupakan kepribadian yang suka menolong dan mudah percaya dengan orang lain (Costa \& Mcrae, 1992). Sedangkan, gaya manajemen konflik integrating adalah gaya manajemen konflik yang dilakukan dengan cara bertukar pendapat (Rahim, 2001). Osuch dan Lewandawski (2004) mengatakan bahwa pihak yang dapat bersosialisasi dan dapat dipercaya akan lebih mudah menlakukan pertukaran pendapat.

Hasil analisis selanjutnya menunjukkan bahwa individu dengan openness yang tinggi juga berkorelasi dengan gaya manajemen konflik obliging dan dominating. Alasan yang dapat menjelaskan korelasi keduanya adalah pertama, kepribadian openness merupakan kepribadian yang menyukai hal baru dari dirinya juga meliputi ide dan opini dari orang lain (Feist \& Feist, 2009), akan tetapi, ketika individu ini menyadari bahwa persepsi dia salah dan pendapat pihak lain benar maka kemungkinan untuk mengikuti pihak lawan dapat terjadi. Pendapat ini sesuai dengan penjelasan Rahim (2001) mengenai gaya manajemen konflik obliging, di mana salah satu keadaan yang sesuai untuk menggunakan ini adalah ketika individu menyadari bahwa kemungkinan kita berada di posisi yang salah (Rahim, 2002). Kedua, selain individu yang terbuka dengan hal baru, individu dengan kepribadian ini juga merupakan individu yang apa adanya dan bebas/tidak terikat (Costa \& Mcrae, 1992) sehingga untuk melindungi kebebasannya individu ini akan cenderung menguasai pihak lawan. Hal ini sejalan dengan pengertian yang diberikan Rahim (2001) bahwa gaya manajemen konflik dengan cara menguasai pihak lawan karena menginginkan kemenangan sepihak adalah gaya manajemen konflik dominating.

Terakhir, derajat kepribadian extraversion berkorelasi negatif terhadap gaya manajemen konflik avoiding sedangkan pada kepribadian neuroticsm berkorelasi positif dengan gaya manajemen konflik avoiding. Beberapa alasan yang dapat menjelaskan korelasi keduanya yaitu pertama, hal ini dapat dikarenakan gaya manajemen konflik avoiding merupakan gaya manajemen konflik dengan cara menghindar (Rahim, 2001), sedangkan kepribadian extraversion merupakan yang senang bersosialisasi, aktif dan optimis akan tujuannya (Costa \& Mcrae, 1992). Sehingga, jika dihadapkan dengan konflik individu ini akan cenderung berusaha untuk menyelesaikan konfliknya daripada menghindar. Kedua, kepribadian neuroticsm merupakan kepribadian yang cenderung pencemas, emosional, dan tempramental (Feist \& Feist, 2009). Empat dari gaya manajemen konflik yang diajukan Rahim memiliki fokus yang pasti terhadap konflik, sedangkan kecemasan dan rasa tidak aman yang dimiliki pribadi ini dapat mengarahkannnya kepada pelarian diri (Goel \& Khan, 2012) sehingga untuk mendapatkan rasa aman individu ini tidak berfokus pada dirinya maupun orang lain, hal seperti ini lebih mengarah kepada gaya manajemen konflik avoiding karena gaya ini tidak berfokus pada siapapun dan memilih untuk menghindari masalah (Rahim, 2001).

Hubungan yang dihasilkan dari dimensi kepribadian kepribadian dan gaya manajemen konflik memiliki kekuatan yang sangat kecil. Sedikitnya nilai yang 
ada dari kedua variabel membuktikan bahwa ada faktor lain yang lebih menentukan daripada kepribadian. Hal ini juga dikuatkan oleh Deutch (2000) yang mengatakan bahwa individu sekarang tidak semudah dahulu, terlepas dari faktor agama,ras dan etnis seseorang ada faktor lain yang harus diperhitungkan yaitu tempat dimana dia tinggal juga mempengaruhi cara seseorang berfikir, hal ini yang sering disebut dengan subjektif culture.

Adanya faktor yang lebih penting daripada kepribadian dalam menentukan gaya manajemen konflik seseorang, dapat menjadi landasan bahwa tes kepribadian dalam seleksi penerimaan kerja atau dalam bidang apapun yang membutuhkan kemampuan mengatasi konflik, tidak dapat menjadi penentu yang pasti bagi pihak yang membutuhkan.

Sebagai kesimpulan, hasil penelitian ini menunjukkan bahwa dimensi-dimensi kepribadian tertentu dapat menentukan cara individu untuk menyelesaikan konflik. Orang yang memiliki kepribadian openness dan conscientiousness yang tinggi merupakan orang yang cukup fleksibel. Di satu sisi, ia dapat melakukan gaya manajemen konflik yang bersifat win-win solution (integrating), atau jalan tengah yang tidak terlalu merugikan pihak-pihak yang terlibat konflik (compromising). Di sisi lain, ia dapat melakukan pendekatan yang mendominasi (dominating) pihak lain, apabila diperlukan. Selain itu, dimensi kepribadian extraversion juga memiliki dampak terhadap kecenderungan gaya manajemen konflik, di mana orang yang tinggi pada dimensi kepribadian ini akan lebih mungkin melakukan pendekatan integrating dalam menyelesaikan konflik. Oleh karena itu, untuk memperkecil terjadinya konflik antar individu dapat dengan mengetahui karakter pihak lawan sehingga dapat mengetahui gaya manajemen konflik yang sesuai untuk karakter tertentu. Serta kepribadian juga menjadi salah satu faktor yang digunakan dalam penilaian seleksi kerja oleh perusahaan, tetapi dengan kecilnya nilai kontribusi kepribadian dalam gaya manajemen konflik menunjukkan bahwa pihak terkait harus lebih memikirkan faktor lain yang lebih berkontribusi untuk mengetahui gambaran gaya manajemen konflik calon anggotanya.

\section{DAFTAR PUSTAKA}

Ahmed, I., Nawaz, M.M., Shaukat, M.Z., \& Usman, A. (2010). Personality does affect conflict handling style: Study of future managers. International Journal of Trade, Economics and Finance,.1(3), 268-270.

Akrami, N., \& Ekehammar, B. (2006). Right-Wing Authoritarianism and Social Dominance Orientation : Their Roots in Big-Five Personality Factors and Facets. Journal of Individual Differences, 27(3), 1-9.

Antonioni, D. (1998). Relationship between the big five personality factors and conflict management styles. International Journal of Conflict Management, 9(4), 336-355.

Burn, S.M. (2004). Groups theory and practice. Canada : Wadsworth

Costa, P.T., \& Mcrae, R. (1992). Four ways five factors basic. Person. Individ, 13( 6), 653-665.

Dayakisni,T., \& Yuniardi, S. (2004). Psikologi lintas budaya. Edisi Pertama. Yogyakarta:UMM Press

Deutch, M., \& Coleman, P.T. (2000). The handbook of conflict resolution. New York : John Wiley \& Sons, Inc

Feist, J., \& Feist,G.J. (2009). Theories of personality. Singapore:McGraw Hill

Field, A. (2009). Discovering statistic using SPSS 3th edition. London : SAGE

Goel, D., \& Khan, I. (2012). Predictive Role of Personality on Conflict Management Strategies of Individuals in IT Sector: Indian Perspective. National Conference on Emerging Challenges for Sustainable Business, 600-622. 
Iqbal, F., Ejaz, S.S., \& Ara, A. (2012). Relationship among personality traits and conflict handling styles of call center representatives and appraisal of existing service model. International Journal of Psychological Studies, 4(4), 27-36.

Lee, K.L. (2008). An Examination between the Relationships of Conflict Management Styles and Employees' Satisfaction. International of Bussiness and Management, 3(9), 11-21.

McRae, R., \& John, O.P. (1992). An introduction to the five-factor model and its applications. Gerontology Research Center, 4940 Eastern Avenue, Baltimore, MD 21224.

Mcshane, S. L \& Glinow, V. (2003). Organizational behaviour. New York : McGraw-Hill Companies,Inc.

Mullins, L.J. (2005). Management and organizational behaviour. England : Prentice Hall

Osuch, K., \& Lewandowski, M. (2004). Personality and conflict management styles: synergy of nomothetic and idiomatic approach. University of Warsaw Journal.

Pervin, L.A., Cervone.D., \& John, O.P. (2005). Personality theory and research.USA: John Wiley \& Sons, Inc

Rahim, M. A. (2001). Managing conflict in organizations (3rd ed.). Westport: Greenwood Publishing Group, Inc.

Schultz, D., \& Schultz, S.E. (1993). Theories of personality. USA: Wadsworth,Inc

Ujan, A.A., Molan, B., \& Nugroho,St. (2011). Multikulturalisme belajar hidup bersama dalam perbedaan. Jakarta Barat : PT.Indeks

Winardi. (2007). Manajemen konflik (Konflik perubahan dan pengembangan). Bandung: CV. Mandar Maju 